\title{
The Effect of the Atmospheric and Cloud Properties on the Retrieval of Fog Microphysics at Night for MSG/SEVIRI: A Sensitivity Test Using LibRadtran
}

\author{
Aliton Oliveira da Silva', Augusto Jose Pereira Filho', Hugo Abi Karam² \\ ${ }^{1}$ Departamento de Ciências Atmosféricas, Instituto de Astronomia, Geofísica e Ciências Atmosféricas, Universidade de São Paulo, \\ São Paulo, Rua do Matão 1226, São Paulo, Brazil \\ ${ }^{2}$ Centro de Ciências Matemáticas e da Natureza, Instituto de Geociências, Federal Universidade Federal do Rio de Janeiro, Rio de \\ Janeiro, Rua Athos da Silveira Ramos 274, Rio de Janeiro, Brazil \\ Email: aliton.silva@iag.usp.br, augusto.pereira@iag.usp.br, hugo@igeo.ufrj.br
}

How to cite this paper: da Silva, A.O., Filho, A.J.P. and Karam, H.A. (2021) The Effect of the Atmospheric and Cloud Properties on the Retrieval of Fog Microphysics at Night for MSG/SEVIRI: A Sensitivity Test Using LibRadtran. Atmospheric and Climate Sciences, 11, 441-457.

https://doi.org/10.4236/acs.2021.113026

Received: April 21, 2021

Accepted: June 6, 2021

Published: June 9, 2021

Copyright $\odot 2021$ by author(s) and Scientific Research Publishing Inc. This work is licensed under the Creative Commons Attribution International License (CC BY 4.0).

http://creativecommons.org/licenses/by/4.0/ (c) (i) Open Access

\begin{abstract}
The simplest way of building a look-up table (LUT) for the retrieval of cloud microphysical properties is to use a standard atmospheric profile and vertically uniform cloud microphysics. Such an assumption has been demonstrated to be incoherent with in-cloud observations. This paper aims to show the effect of some atmospheric conditions associated with fog as well as its macro-and microstructure on brightness temperature (BT) for the MSG/ SEVIRI satellite using libRadtran. The sensitivity tests were performed by gradually changing some features from the initial data, such as cloud cover, total water vapor column, thermal inversion intensity, fog depth, fog microstructure, and others. The results revealed that some variables can cause significant variations on BT and, consequently, discrepancies in the retrieval of fog microphysical properties. Also, a variation as high as $0.5^{\circ} \mathrm{C}$ was found on BT just by switching uniform to the non-uniform profile of fog microphysics depending on the channel, the droplet size, and optical thickness.
\end{abstract}

\section{Keywords}

Fog Microphysics, MSG/SEVIRI, Sensitivity Test, LibRadtran

\section{Introduction}

Fog is a physical phenomenon that occurs as a result of a cloud formation close to the earth's surface and is usually identified when horizontal visibility is below 
$1 \mathrm{~km}$ according to [1]. Fog can cause serious problems to vegetation and traffic systems as in [2] and [3]. The knowledge of fog microphysical properties has led to a better understanding of fog development stages.

Satellites have become a powerful tool for overcoming the problems for the near real-time monitoring of fog spatial coverage and microphysical recovery. Daytime fog detection and microphysical recovery consist of combining visible and near-infrared channels so that visible channels are more sensitive to fog optical thickness and near-infrared channels are more sensitive to fog droplet size as in [4] [5] [6]. In cases where $3.9 \mu \mathrm{m}$ wavelength is used for the daytime procedure, a correction for removing the longwave signals is needed according to [7]. The nighttime procedure usually requires atmospheric window channels at $3.9 \mu \mathrm{m}$ and $10.8 \mu \mathrm{m}$ as in [8] and [9]. [10] used a radiative transfer model to identify the ideal channel combinations for the retrieval of low cloud microphysical properties in the infrared spectral range and they found that MSG infrared channels were more sensitive to particle size than to optical thickness. Such a result showed that the retrieval of cloud microphysical properties at night can be a task somewhat difficult. The difficulty is associated with the understanding of the roles of each variable in the microphysical retrieval. So that they vary as the temperature of the surface and the azimuth angle can generate convolutions in the microphysical reference and this can make microphysical recovery difficult since convolutions can generate ambiguous results. This means that for the same brightness temperature, it is possible to obtain two distinct results of droplet size and liquid water content.

To keep simple the building of a look-up table (LUT) for the retrieval of cloud microphysical properties, generally standard atmospheric profiles from Air Force Geophysics Laboratory (AFGL) and vertically homogeneous profile of fog microstructure are taken into account in the radiative transfer calculations as in [11] and [12]. [13] mentioned that such simplifications are acceptable because the radiance that reaches the satellite's sensor carries not enough information to account for the particle sizes and distribution inside the cloud.

Fogs are observed in various atmospheric conditions during their lifespan due to the thermal, radiative, and dynamic processes according to [14]. Radiation fogs generally form under a clear sky where water vapor saturation and temperature inversion are likely to happen as a result of radiative cooling as in [15]. Besides, the vertical profile of fog microstructure can also appear in several different ways according to [16]. In the last decade, authors are accounting for the vertical heterogeneity of cloud microstructure in the radiative transfer calculations, but the effect of disregarding such heterogeneities was not addressed for the MSG/SEVIRI sensors.

For that reason, this paper aims to present the effects of atmospheric conditions associated with fog such as temperature inversion, fluctuations in total water vapor column (TWV) as well as the effect of fog geometrical thickness and microstructure on MSG9 brightness temperature (BT), since generally no special 
care is devoted to these variables in the radiative transfer calculations.

\section{Data and Methods}

\subsection{LibRadtran}

LibRadtran (Library for Radiative Transfer) is a sophisticated numeric model for radiative transfer calculations as in [17]. The routine termed uvspec is the main tool of the libRadtran package, in which different types of atmospheric geometry approximation, radiation sources, and radiative transfer equation solvers can be selected. The sensitivity tests were conducted considering a plane-parallel geometry, where the earth's curvature is neglected and all the atmospheric layers are considered horizontally homogeneous.

The DISORT (Discrete Ordinate Radiative Transfer) was the method used for solving the radiative transfer equation, as described in detail by [18] and [19]. A molecular absorption parameterization for MSG satellites called REPTRAN (Representative wavelengths absorption parameterization) was added by [20]. The implementation of REPTRAN showed a low mean error for the MSG/ SEVIRI channels when compared against high spectral resolution simulations and that makes it suitable for the tests. The argument list for libRadtran simulation is shown in Table 1.

\subsection{Vertical Profile of Temperature and Humidity}

Radiative transfer calculations require atmospheric properties such as vertical profiles of pressure, air temperature, and gas concentration, as well as cloud microphysics. The atmospheric standard profile for the tropical region (AFGLT) of [21] was modified at altitudes below $25 \mathrm{~km}$ to adequate a radiosonde with low-level thermal inversion, with which fogs are usually associated according to [22] and [23]. Also, concentrations of ozone, oxygen, carbon dioxide, and nitrogen dioxide were kept the same as in the AFGLT profile, as well as all other trace gases.

The radiosonde presented in Figure 1 was attached to the upper atmosphere of the AFGLT standard profile so that a smooth transition between the two profiles was achieved. Geopotential height was recalculated as a function of the temperature and pressure to keep the hydrostatic balance and increase the accuracy of the simulations. The TWV was kept as observed in the radiosonde (73.4

Table 1. General arguments used in the radiative transfer calculations.

\begin{tabular}{cc}
\hline Arguments & Input description \\
Solver & Disort \\
Source & Thermal spectral range \\
Mol. absorption & REPTRAN applied to MSG9 \\
Sat. channels & IR_039, IR_087, IR_108 and IR_120 \\
Sat. geometry & 57.6 (zenith) and 69.0 (azimuth) \\
Aerosol & Urban and fall-winter \\
\hline
\end{tabular}




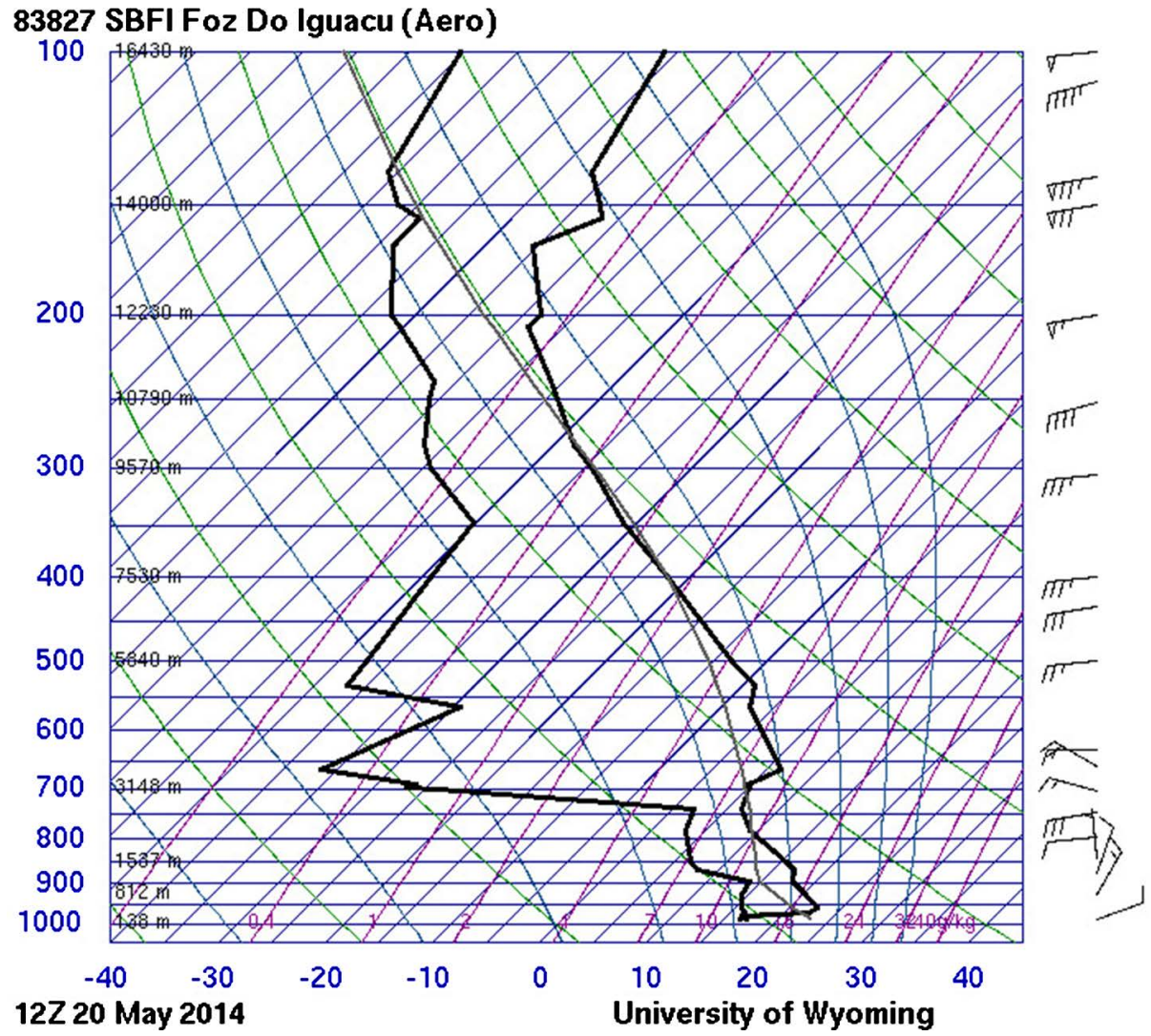

Figure 1. Radiosonde is used as input data in the libradtran software. Source: Wyoming Soundings.

$\mathrm{kg} \cdot \mathrm{m}^{-2}$ ) and the air temperature at the first level was considered as the surface temperature $\left(17.2^{\circ} \mathrm{C}\right)$. In the closest inversion layer to the ground, the top-base temperature difference was $6^{\circ} \mathrm{C}$ and their heights were $305 \mathrm{~m}$ and $58 \mathrm{~m} \mathrm{AGL}$, respectively.

\subsection{Vertical Profile of LWC and Droplet Size}

The vertical distribution of liquid water content (LWC) and particle size was obtained from a cloud model. The shapes of the microphysical profiles were a result of a set of simulations performed for foggy situations. Figure 2 shows the minimum and maximum values used in the radiative transfer calculations. The particle size and LWC were not less than $1 \mu \mathrm{m}$ and $1 \mathrm{mg} \cdot \mathrm{m}^{-3}$ throughout the fog layer, respectively.

The maximum cores of microphysical properties usually were found next to the fog top according to [24] [16] and [25]. However, the maximum core can also be found next to the fog bottom. The shifting core was demonstrated in detail by [26] and [27]. They found that droplet gravitational settling had an important role in shifting the maximum core of LWC and particle sizes downward.

\subsection{Description of the Sensitivity Tests}

\subsubsection{Fractional Cloud Cover}

This sensitivity test consists of understanding the effect of cloud cover on BT 

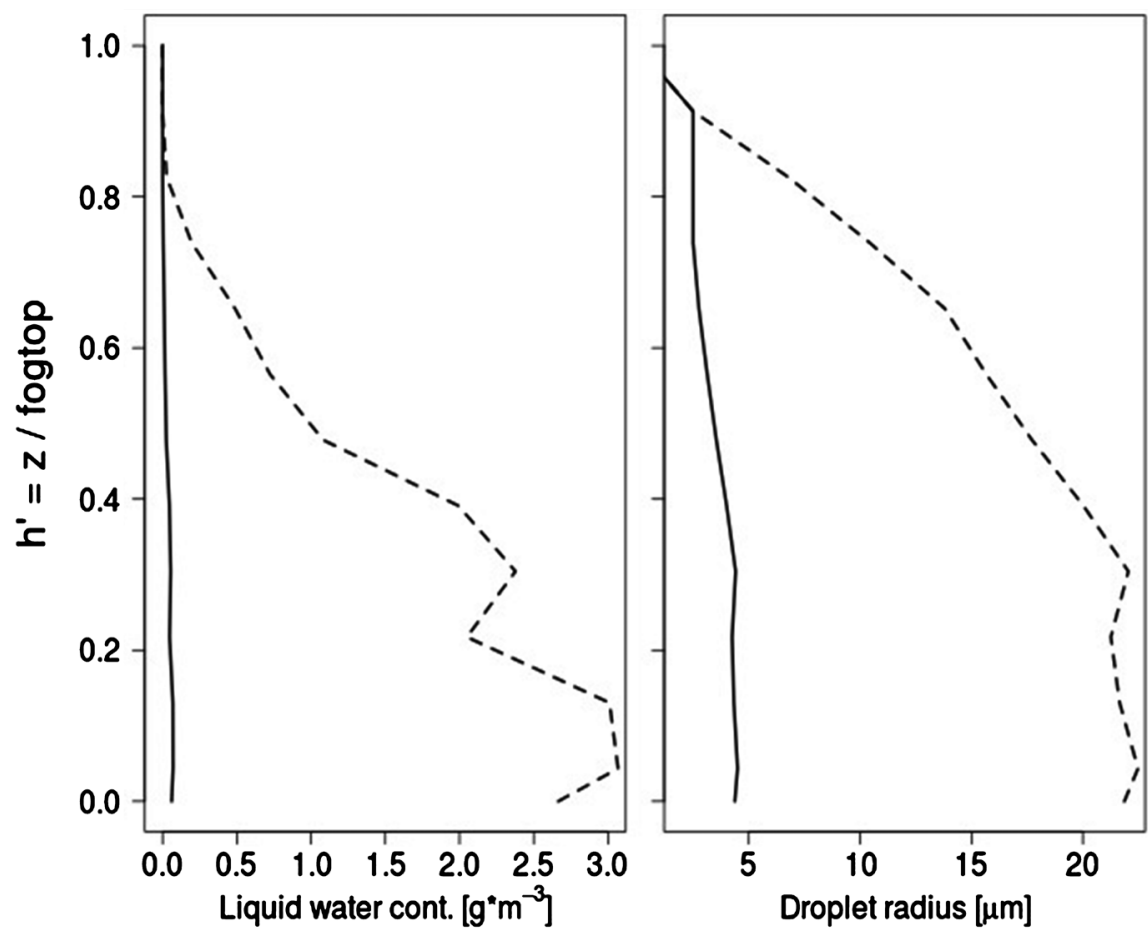

Figure 2. Vertical profile of liquid water content and droplet radius used as input data in the libradtran software. The solid line is the minimum bound and the dashed line is the maximum bound.

and how such changes can alter fog microphysical retrieval. The effect of cloud fraction on the BT was performed by simple subtraction of a pixel half-covered by fog from a pixel fully covered by fog. The cloud input data for this analysis was a $100 \mathrm{~m}$-deep fog with its microstructure varying in the fog layer (Figure 2).

\subsubsection{Fog Depth}

The fog depth sensitivity test was conducted by keeping the same atmospheric profile data and changing the fog data. In the fog data, no modification was done to the LWC and droplet size profiles, which means that only the distance between the two levels was changed. Besides, only the fog depth was changed. The fog depths considered were $50 \mathrm{~m}, 100 \mathrm{~m}, 150 \mathrm{~m}$. As a result of changing the distances between the levels, just LWP and optical depth were recalculated, whereas the effective radius was kept the same. The radiative transfer calculations were performed for fog depths of $50 \mathrm{~m}, 100 \mathrm{~m}$, and $200 \mathrm{~m}$. The effect of fog depth was analyzed by subtracting the BT of the deepest fogs $(100 \mathrm{~m}$ and $200 \mathrm{~m}$ ) from the shallowest one $(50 \mathrm{~m})$. From that, we can see two aspects: the effect of fog growth/dissipation and the effect of placing the fog top above the inversion base.

\subsubsection{Total Column Water Vapor}

The TWV was calculated as a function of air temperature and relative humidity. In this sensitivity test, the variation of the water vapor content was just caused by the changes in air temperature, which implies no modification in relative humidi- 
ty. The relative humidity was kept constant at $100 \%$ next to the earth's surface throughout the whole experiment. The profile of air temperature was changed at the level right above the inversion base $(970 \mathrm{hPa})$ up to the level whose temperature was the same as at the inversion base $(868 \mathrm{hPa})$. The air temperature between the mentioned levels was modified in a way that the calculated TWV was 71.7 $\mathrm{kg} \cdot \mathrm{m}^{-2}, 72.1 \mathrm{~kg} \cdot \mathrm{m}^{-2}$, and $73.4 \mathrm{~kg} \cdot \mathrm{m}^{-2}$. Subsequently, to remove the effect of changing temperature, the TWV was kept constant in $71.7 \mathrm{~kg} \cdot \mathrm{m}^{-2}$ for the same temperature variations, so that only the pure effect of TWV could be addressed in this experiment. By subtracting the BT of higher contents from lower ones presented above $\left(\Delta \mathrm{TWV}=72.1\right.$ minus $71.7=0.4 \mathrm{~kg} \cdot \mathrm{m}^{-2}$ and so on), we can analyze the effect of increasing water vapor content in the fog layer. The lowest increment in TWV was $0.4 \mathrm{~kg} \cdot \mathrm{m}^{-2}$ and the highest increment was $2.7 \mathrm{~kg} \cdot \mathrm{m}^{-2}$.

\subsubsection{Vertical Fog Microphysics}

This sensitivity test took into account two vertical profiles of fog microphysics: the first one is vertically homogeneous and the other is vertically heterogeneous. The homogeneous profile has its droplet size and liquid water content constant throughout the fog layer. The heterogeneous profile had its droplet size and liquid water content varying throughout the fog layer (Figure 2).

The vertical distribution of LWC for the homogeneous profile was calculated as a function of geometric fog depth and liquid water path (LWC $=\mathrm{LWP} / \Delta \mathrm{Z}$ ). The vertical profile of effective radius was calculated as a function of fog optical depth and liquid water path ( $\left.\mathrm{reff}=\mathrm{C}^{*} \mathrm{LWP} / \tau\right)$. Both of the profiles (heterogeneous and homogeneous) were set up in a way where LWP and effective radius were maintained the same for a fog depth of $100 \mathrm{~m}$.

\subsubsection{Surface Temperature}

The air temperature at the first level in the atmospheric input data was considered as the surface temperature. In this sensitivity test, the surface temperature was modified and the atmospheric pressure was kept unchanged, so the $\mathrm{z}$-coordinate needed to be recalculated to maintain the hydrostatic equilibrium and increase the accuracy of the calculations. The surface temperature was changed around that observed in the radiosonde so that we can see the effect of increasing the surface temperature from $15^{\circ} \mathrm{C}$ to $17^{\circ} \mathrm{C}\left(\Delta \mathrm{T}=2^{\circ} \mathrm{C}\right), 15^{\circ} \mathrm{C}$ to $18^{\circ} \mathrm{C}$ $\left(\Delta \mathrm{T}=3^{\circ} \mathrm{C}\right)$, and $17^{\circ} \mathrm{C}$ to $18^{\circ} \mathrm{C}\left(\Delta \mathrm{T}=1^{\circ} \mathrm{C}\right)$. For this test, the heterogeneous profile and $100 \mathrm{~m}$-deep fog were used.

\subsubsection{Temperature Inversion Intensity}

In this experiment, the profile of air temperature was proportionally changed at the level right above the inversion base $(970 \mathrm{hPa})$ up to the level whose temperature was the same as at the inversion base $(868 \mathrm{hPa})$, while keeping the level of the inversion top the same. The temperature inversion intensity was set to be 2 , 3 , and $6 \mathrm{~K}$. To not introduce the effect of water vapor content, the TWV was kept constant at $71.7 \mathrm{~kg} \cdot \mathrm{m}^{-2}$. For this test, the heterogeneous profile and 100 $\mathrm{m}$-deep fog were used. 


\section{Results}

The sensitivity tests consist of analyzing the effect of changing a particular variable in the initial atmospheric input data on the MSG9 BT. Six main sensitivity tests were performed. Fractional cloud cover and fog depth experiments were the only ones in which no change in the atmospheric or cloud input data was applied.

\subsection{Effect of the Fractional Cloud Cover}

The effect of decreasing cloud cover from $100 \%$ to $50 \%$ is to increase the BT. This occurs because as foggy area reduces in the pixel, more and more radiation emitted by the earth's surface can reach the top of the atmosphere. IR_039 and IR_087 are the most sensible channels to the cloud cover in the satellite pixel. Furthermore, the reduction of cloud cover within the pixel results in greater differences of BT for droplets, which might be associated with Rayleigh/Mie scatterings. Small droplets show more sensibility than bigger ones and droplet radius less than $10 \mu \mathrm{m}$ shows a difference greater than $0.5 \mathrm{~K}$ (Figure 3 ).

The changing in cloud cover can cause significant errors in fog droplet size retrieval (Figure 4). For example, BT of $288.7 \mathrm{~K}$ and $305.0 \mathrm{~K}$ for the channels IR_108 and IR_039, respectively, the retrieved radius would be $20 \mu \mathrm{m}$ for a $100 \%$ cloud-covered pixel and $10 \mu \mathrm{m}$ for a $50 \%$ cloud covered pixel, whilst LWP was practically kept unchanged.

\subsection{Effect of the Fog Depth}

As can be seen in Figure 5, a change in fog depth of $50 \mathrm{~m}$ (100 minus $50 \mathrm{~m}$ )

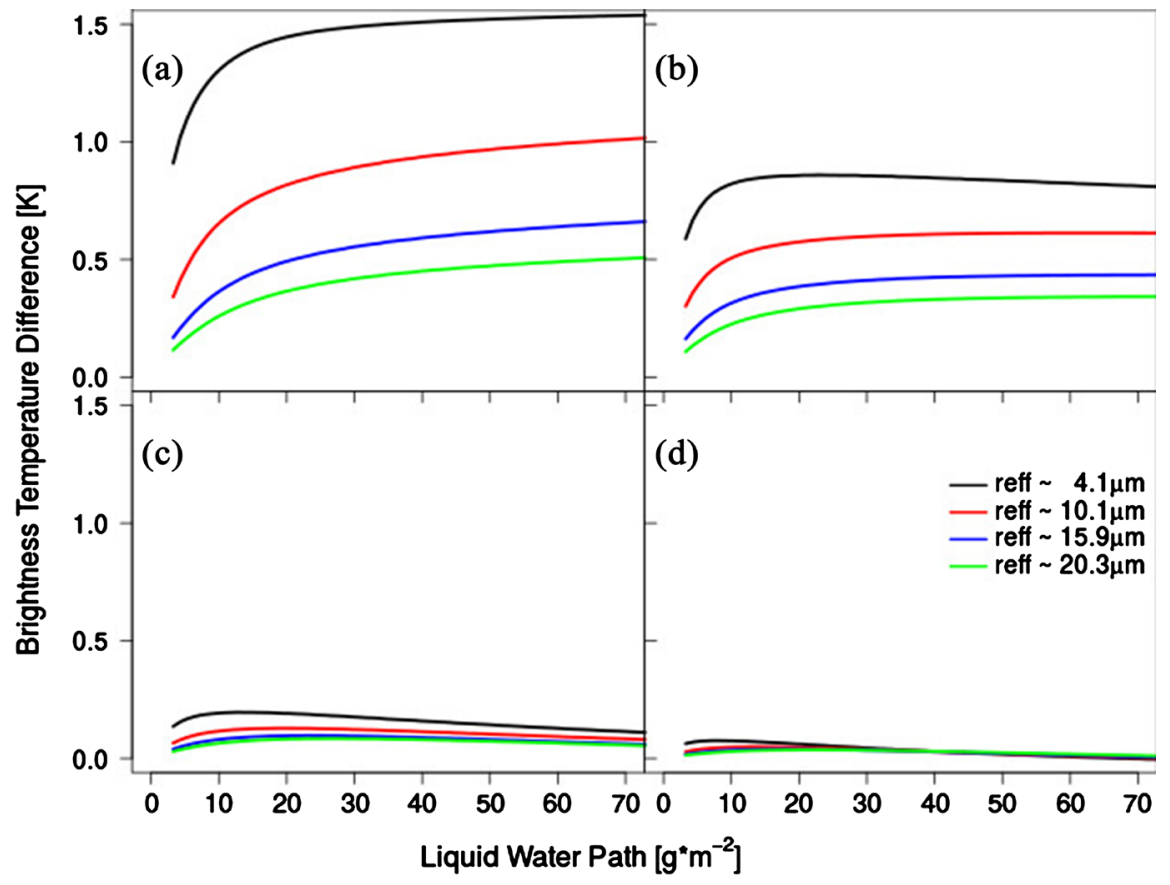

Figure 3. Difference in brightness temperature due to the change on cloud cover from full-filled pixel to half-filled pixel for the MSG channels (a) IR_039, (b) IR_087, (c) IR_108 and (d) IR_120. 


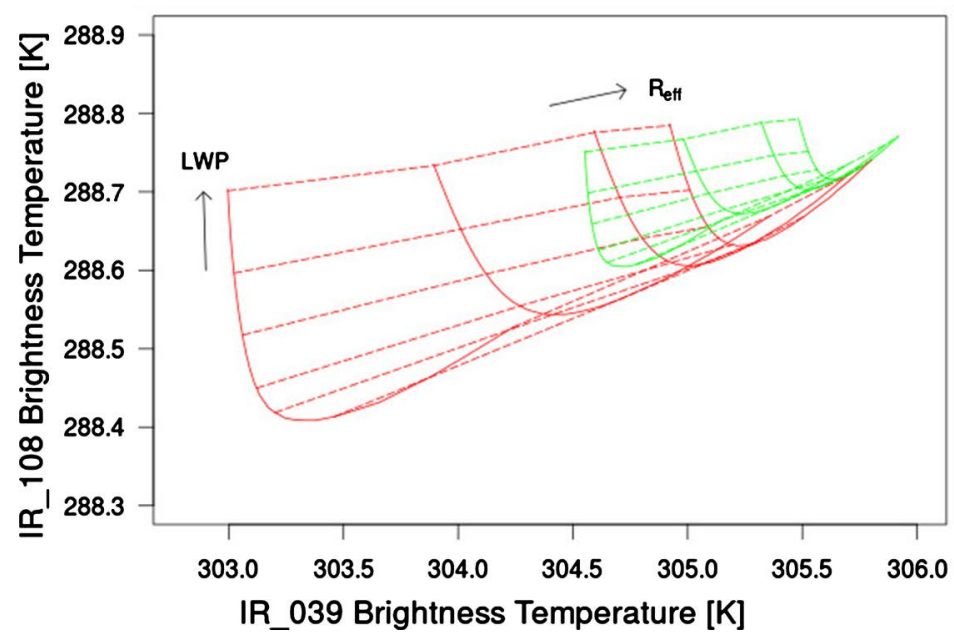

Figure 4. LUT built with IR_108 and IR_039 channels. In red is the LUT for full-filled pixel and in Green is the half-filled pixel. The solid line is for effective radius and the dashed line is for LWP. The arrows indicate the direction where the variables increase.

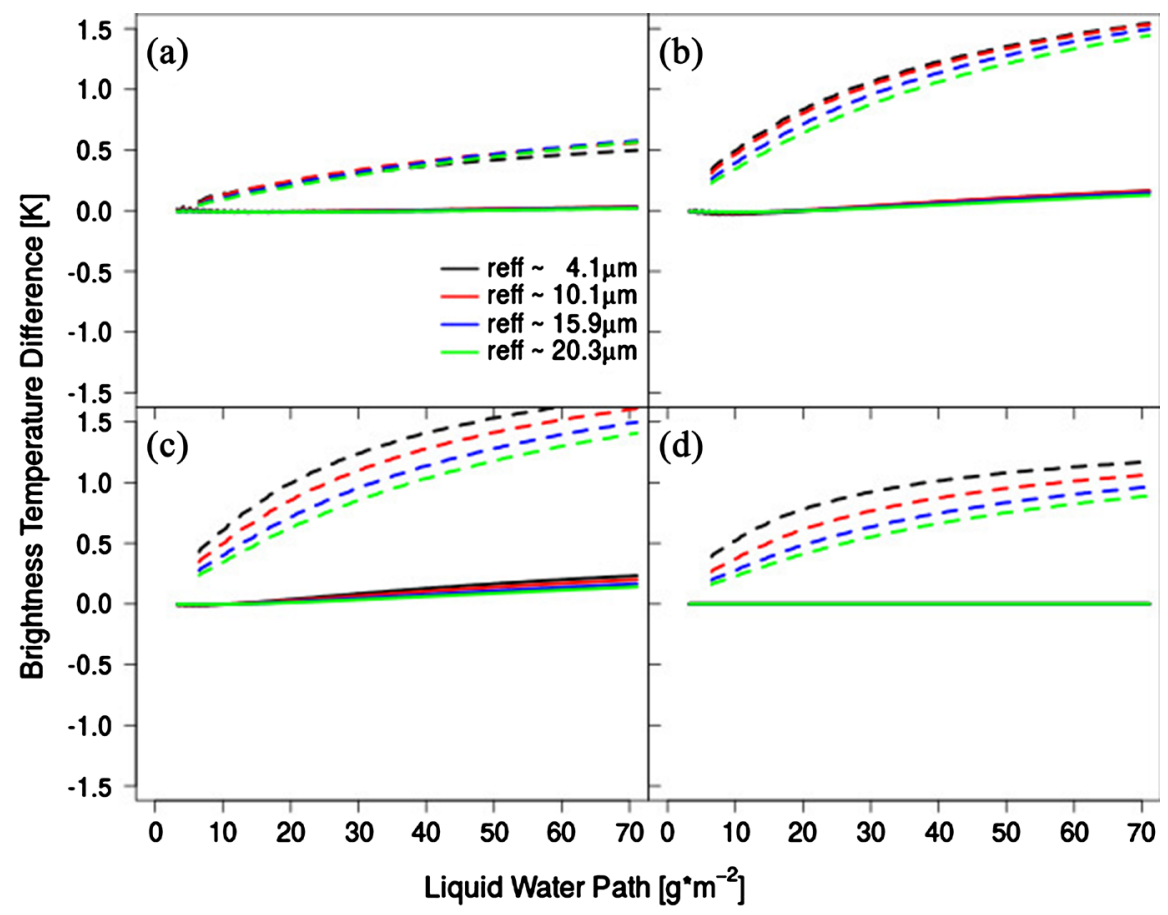

Figure 5. As Figure 3 but regarding the change in fog depth. The solid line is for $\Delta z=50$ $\mathrm{m}$ and the dashed line is for $\Delta \mathrm{z}=150 \mathrm{~m}$.

showed no significant impact on BT for any of the infrared channels. This particular test showed that in a process of building a LUT if one places the fog top just below the inversion base or a few tens of meters above it, no significant change on BT is expected. As the fog top is placed higher in the inversion layer ( 200 minus $50 \mathrm{~m}$ ), an increase up to $1.5 \mathrm{~K}$ can be seen, especially for IR_108 and IR_087 channels. For this particular test, it can be seen that deeper fogs exhibit higher BT than shallower ones for the same optical thickness and droplet size. One possible explanation for that is as the fog top finds higher air temperature 
up in the inversion layer, the emitted radiance increases accordingly to Planck's function and, then, greater BT is observed. In other words, the general monochromatic radiative transfer equation for plane-parallel geometry as in [17] is a function of the attenuation of the radiation beam that passes through the medium, of the multiple scattering of radiation from all hemispheres towards the sensor and of the thermal radiation emitted by the atmosphere at a given altitude. So, the higher the air temperature at a given altitude, the higher the brightness temperature measured by the satellite sensor.

The consequence of shifting the fog top concerning the inversion layer can be seen in Figure 6. For shallower fogs, the LUT starts convoluting and as the fog top reaches higher levels in the inversion layer the LUT starts unfolding. Another important aspect found is that the two LUTs do not overlap each other. It means that depending on where the fog top is placed, the outcome of the LUT can be completely different. These tests illustrate the importance of a good match between atmospheric profile and fog microstructure.

\subsection{Effect of the Total Water Vapor Column}

Figure 7 shows the pure effect of TWV on BT. As can be seen, small changes in water vapor content at low levels of the troposphere can't promote significant variations on BT for any of the window channels. In this experiment, the IR_039 channel showed insignificant sensitivity to water vapor. On the other hand, IR_087, IR_108, and IR_120 channels showed a certain degree of sensitivity for additional moisture in the fog layer, increasing the BT up to $0.4 \mathrm{~K}$. A little change on BT was not enough to cause a significant change in the LUT's outcome.

\subsection{Effect of the Vertical Fog Microphysics}

In this sensitivity test, the homogeneous profile presented higher BT than the heterogeneous one for the same optical thickness and particle size (Figure 8).

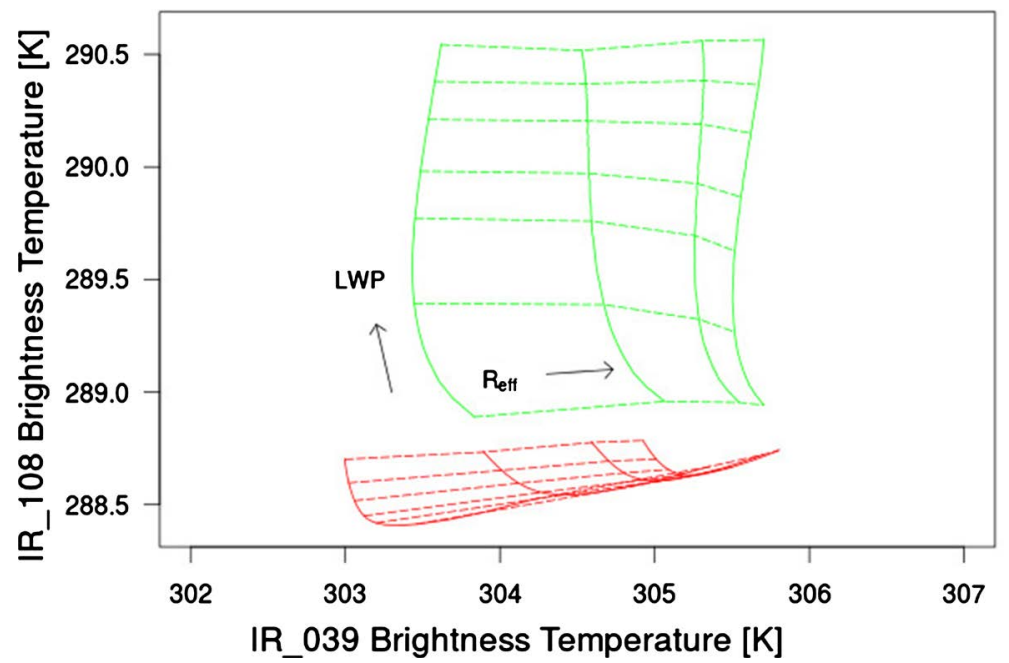

Figure 6. Similar to Figure 4 but regarding the fog depth. In red is the LUT for a fog depth of $100 \mathrm{~m}$ and in green is the LUT for a fog depth of $200 \mathrm{~m}$. 


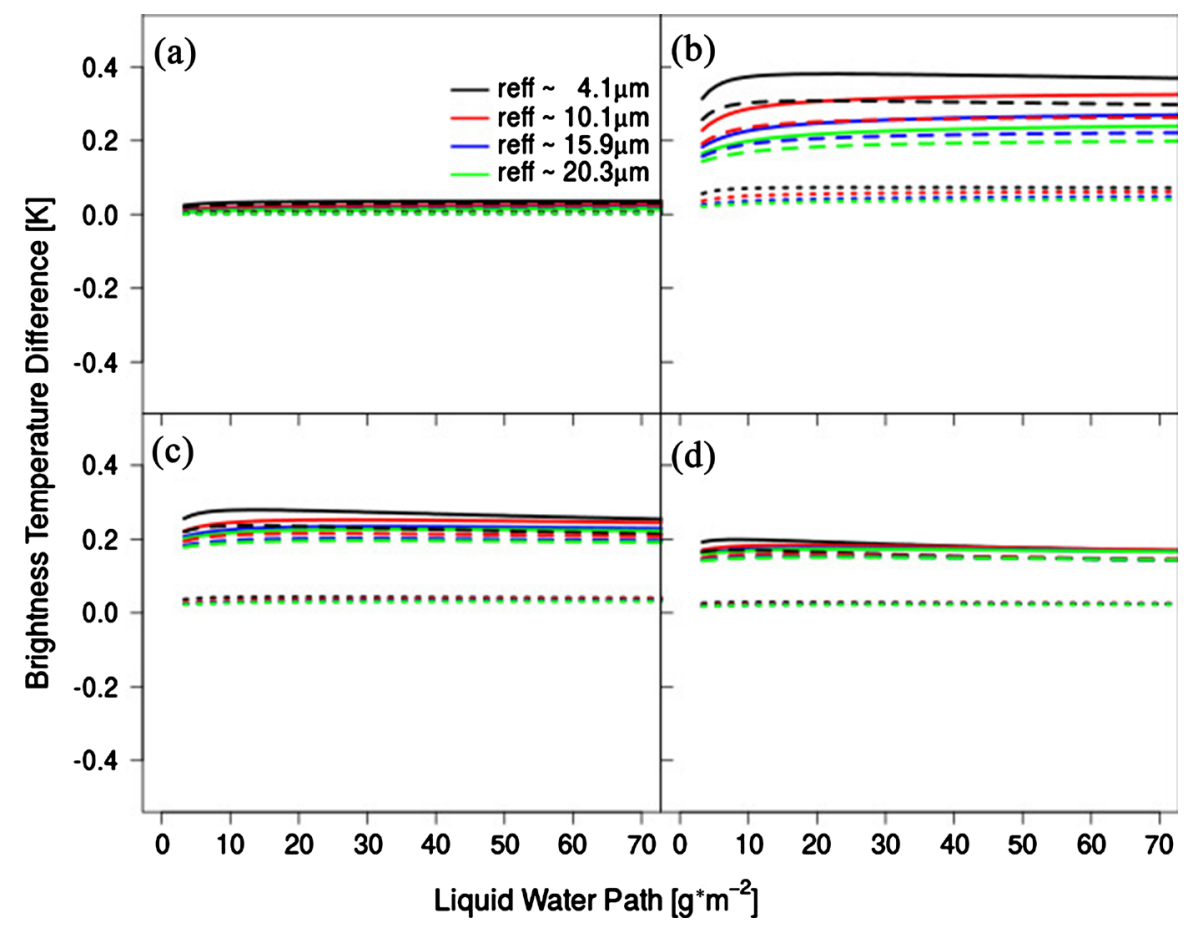

Figure 7. Similar to Figure 3 but regarding the increase in water vapor content of 0.4 $\mathrm{kg} \cdot \mathrm{m}^{-2}$ (dotted line), $1.3 \mathrm{~kg} \cdot \mathrm{m}^{-2}$ (dashed line), and $2.7 \mathrm{~kg} \cdot \mathrm{m}^{-2}$ (solid line).

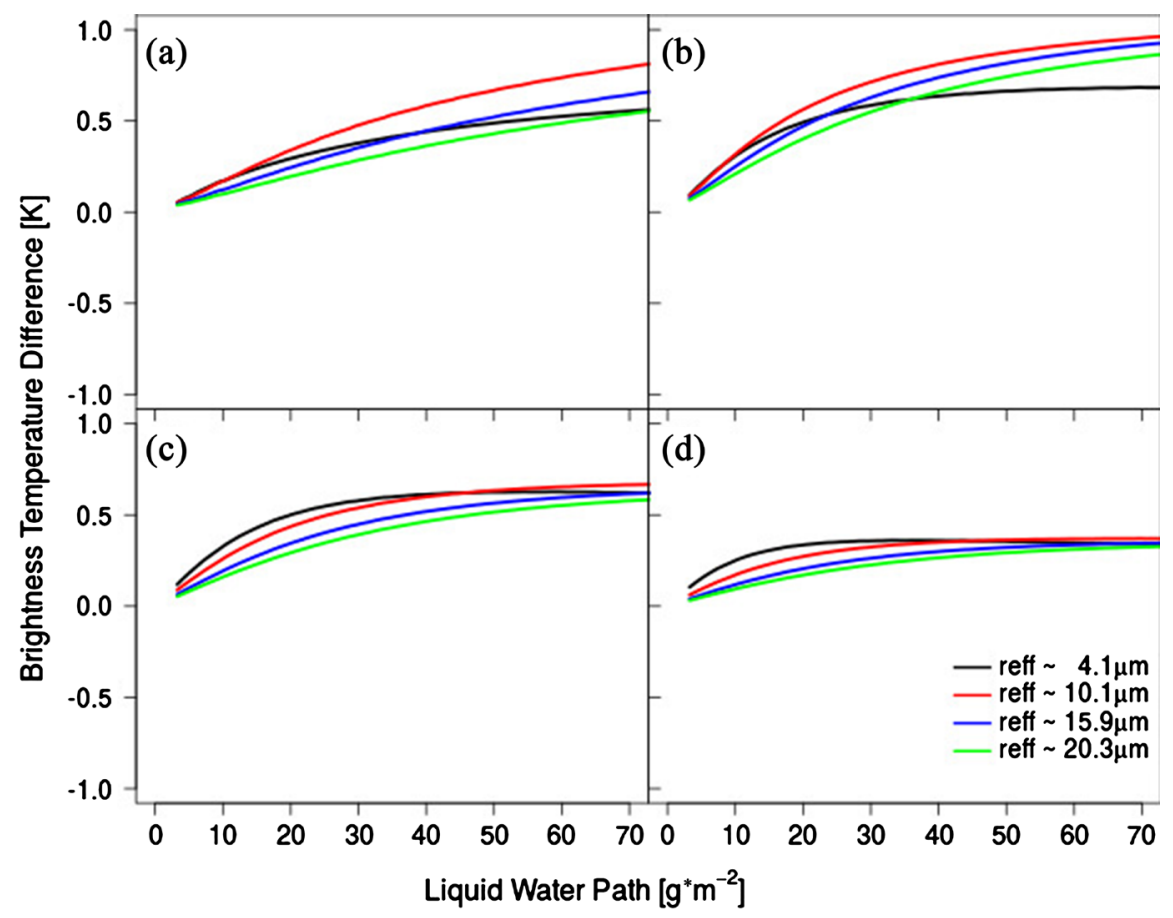

Figure 8. Similar to Figure 3 but regarding the change in the profile of fog microphysics from vertically heterogeneous to homogeneous.

One possible reason is that the homogeneous one had a deeper layer with higher transmissivity at the upper part of the fog layer. As a consequence, more radiation was emitted from the upper part of the fog layer with vertically uniform 
profiles. In general, all window channels had a similar sensitivity. The higher the optical thickness the higher the difference between homogeneous and heterogeneous fog profiles.

This particular test showed that the LUTs overlapped each other in their bottom (homogeneous) and upper (heterogeneous) bounds (Figure 9). Considering a scenario in which the BT for IR_039 and IR_108 are 304.9 and $288.8 \mathrm{~K}$, respectively, the retrieved microphysical properties would be an effective radius of 10 $\mu \mathrm{m}$ and LWP of $10 \mathrm{~g} \cdot \mathrm{m}^{-2}$ for homogeneous profile and an effective radius of 20 $\mu \mathrm{m}$ and LWP of $140 \mathrm{~g} \cdot \mathrm{m}^{-2}$ for heterogeneous one. Therefore, the usage of a homogeneous profile instead of a heterogeneous one caused underestimation of the fog microphysical properties, for this particular scenario.

\subsection{Effect of the Surface Temperature}

It can be seen in Figure 10 that as the fog layer gets optically thinner, more and more radiation emitted by the earth's surface can get through the fog layer and reach the top of the atmosphere, because of high cloud transmissivity. IR_120 channels presented the least sensitivity to the surface temperature increment, whereas IR_087 and IR_108 channels presented the greatest sensitivity, which increased the BT up to $1 \mathrm{~K}$ for a $\Delta \mathrm{T}$ s of $3^{\circ} \mathrm{C}$.

The impact of changing the surface temperature on LUT can be seen in Figure 11 . When the surface temperature was first reduced to $2^{\circ} \mathrm{C}\left(\mathrm{Ts}=15^{\circ} \mathrm{C}\right)$, the inversion base was shifted downward to the earth's surface, which means that the fog layer was completely embedded in the inversion layer. In this particular scenario, the LUT became unfolded when compared to the $17^{\circ} \mathrm{C}$-surface temperature LUT (e.g., Figure 9-LUT for heterogeneous profile). For higher surface temperature $\left(\mathrm{Ts}=18^{\circ} \mathrm{C}\right)$, which can also be thought of as an increase in boundary layer instability, the LUT became even more convoluted.

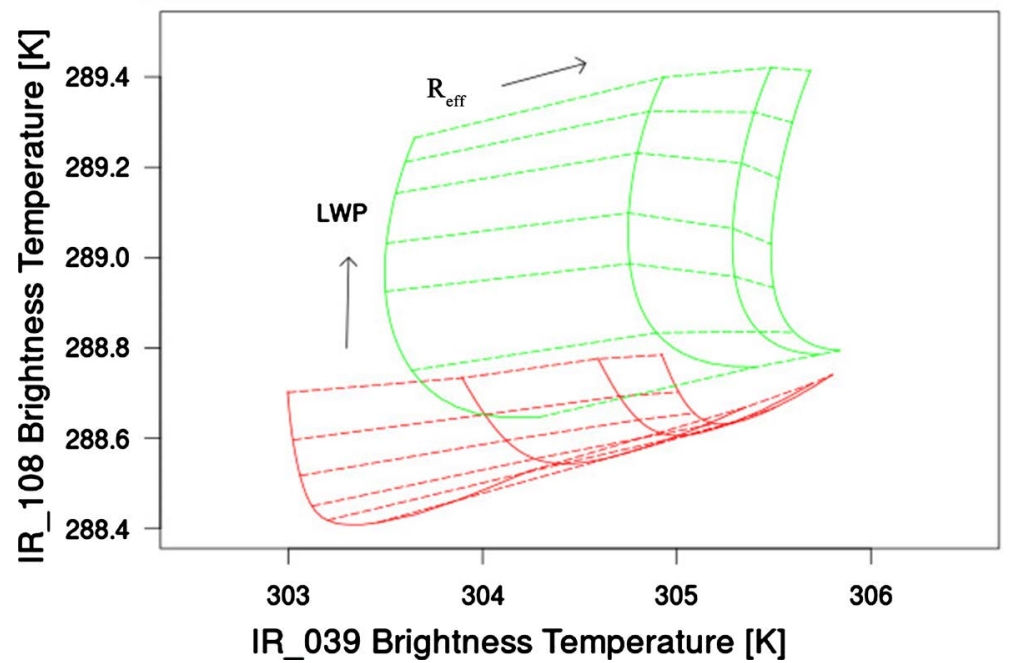

Figure 9. Similar to Figure 4 but regarding the in-fog microstructure. In red is the LUT for the vertically heterogeneous profile and in green is the LUT for the vertically homogeneous profile. 


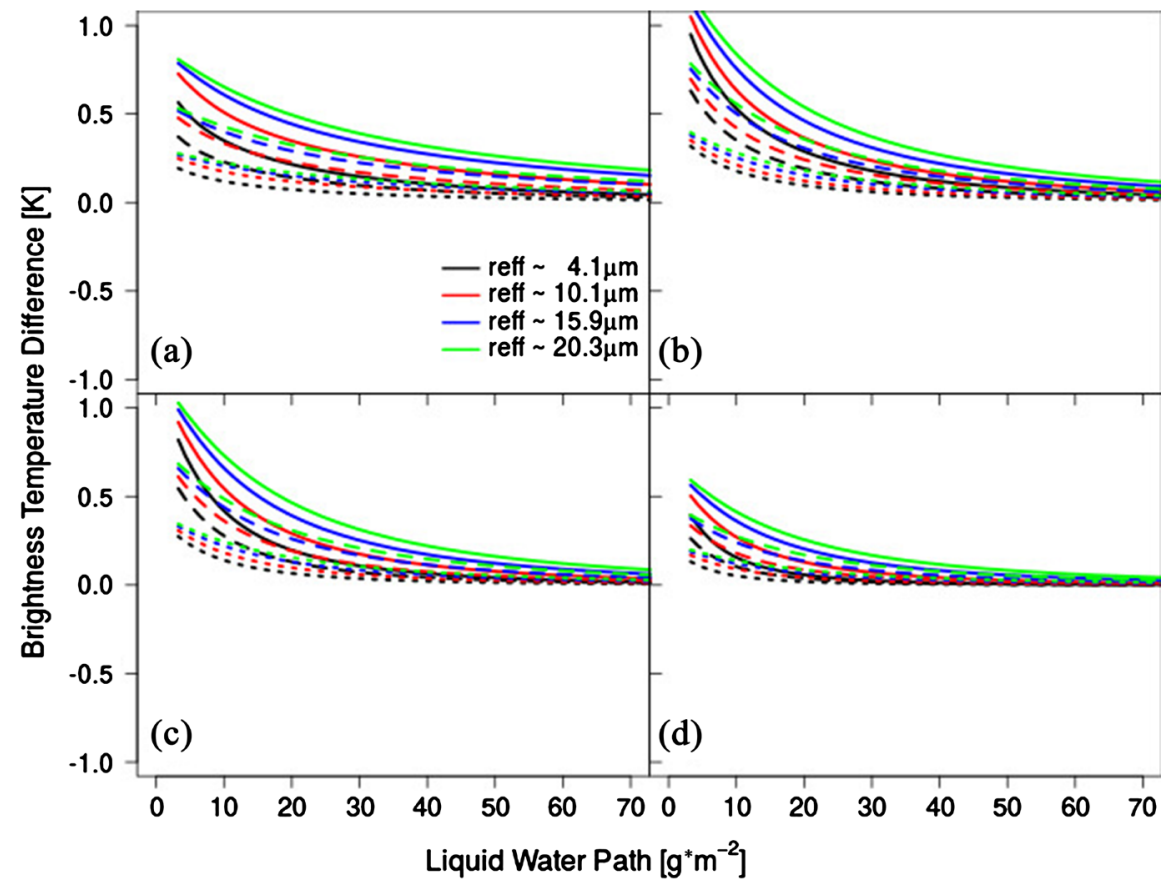

Figure 10. Similar to Figure 3 but regarding the increase in surface temperature is $1 \mathrm{~K}$ (dotted line), $2 \mathrm{~K}$ (dashed line), and $3 \mathrm{~K}$ (solid line).

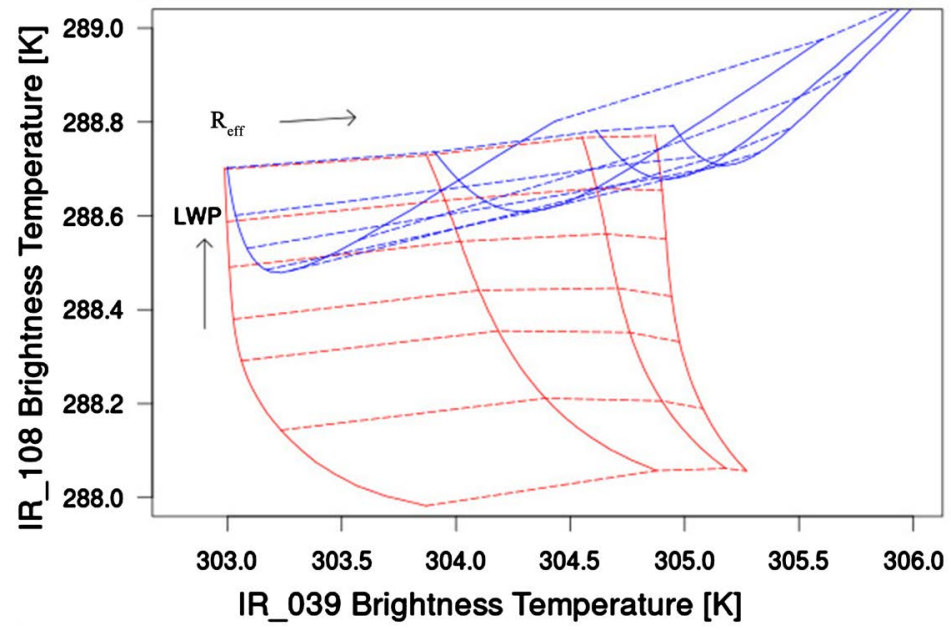

Figure 11. Similar to Figure 4 but regarding the surface temperature. In red is the LUT for a surface temperature of $15^{\circ} \mathrm{C}$ and in blue is the LUT for a surface temperature of $18^{\circ} \mathrm{C}$.

\subsection{Effect of the Temperature Inversion Intensity}

The effect of decreasing the inversion intensity of the radiosonde on BT can be seen in Figure 12. For this particular test, the IR_039 channel had a very low sensitivity to the changes in thermal inversion intensity, due to its low fog emissivity. A reduction of $3^{\circ} \mathrm{C}$ in the inversion intensity caused a decrease as high as $0.5^{\circ} \mathrm{C}$ in the BT, for all the other channels. As can be seen in Figure 13, a typical LUT built with IR_039 and IR_108 channels start flattening as the inversion intensity decreases. This test revealed that different inversion intensities can result in different LUTs. 


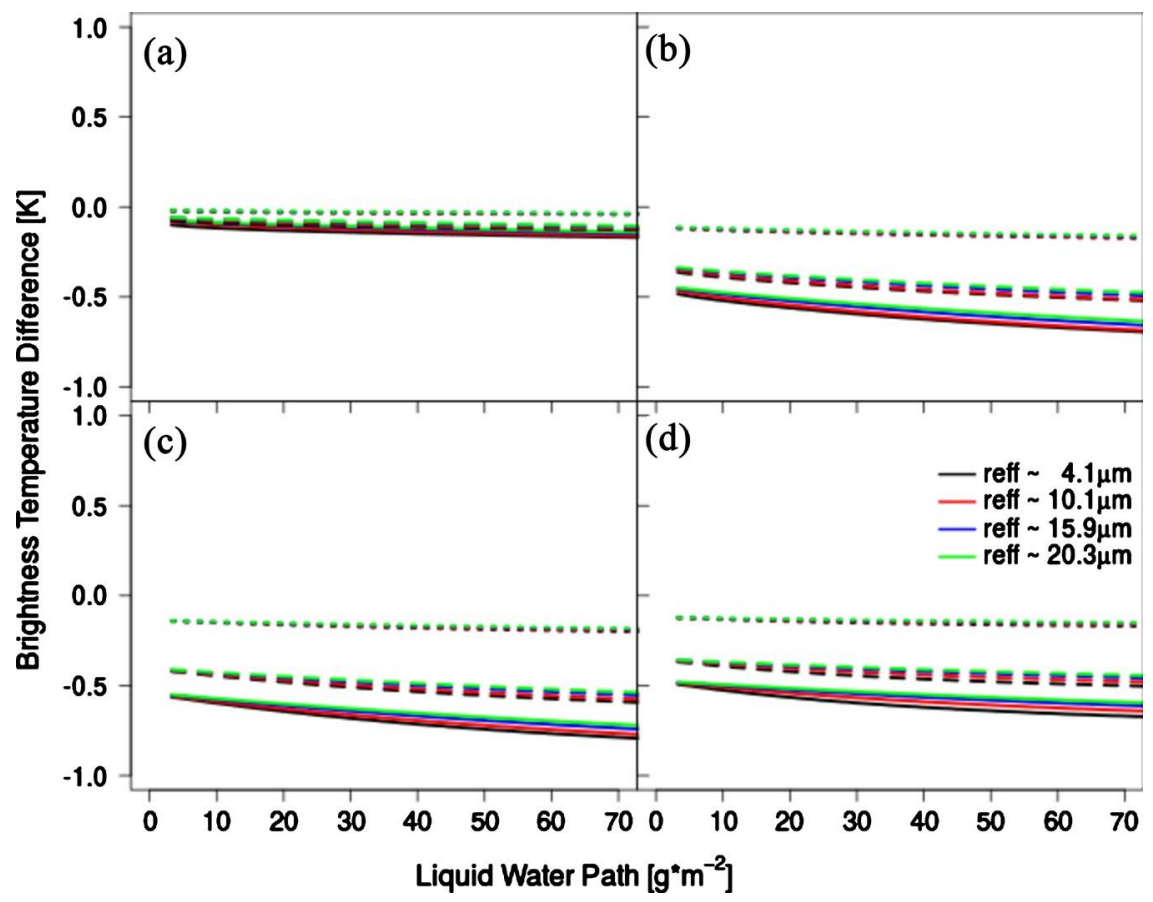

Figure 12. Similar to Figure 3 but regarding the decrease in thermal inversion intensity in $1 \mathrm{~K}$ (dotted line), $3 \mathrm{~K}$ (dashed line), and $4 \mathrm{~K}$ (solid line).

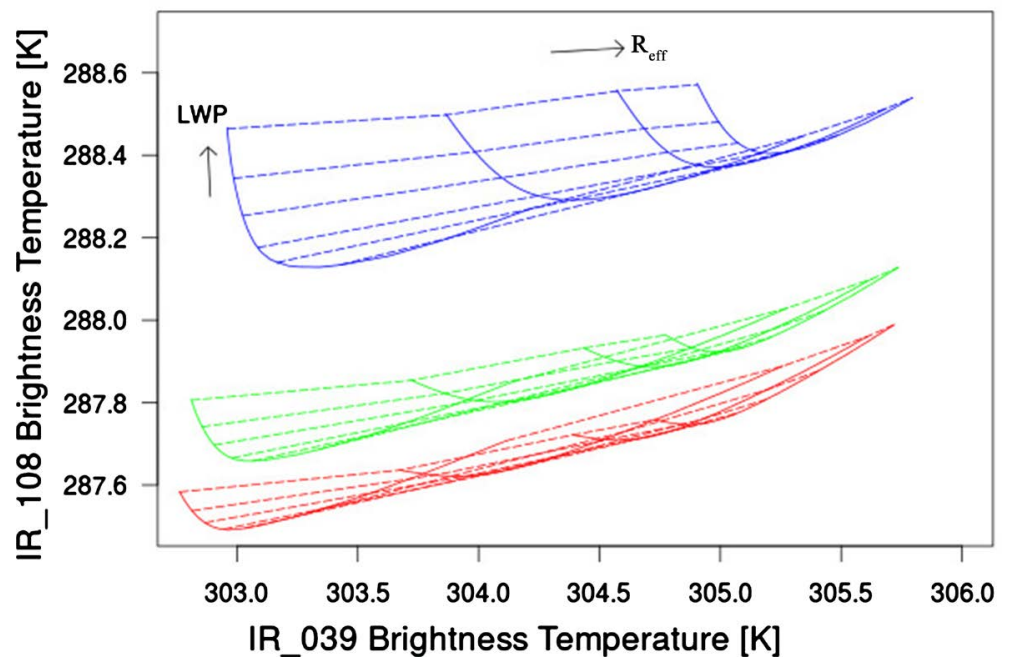

Figure 13. Similar to Figure 4 but regarding the thermal inversion intensity. $\Delta \mathrm{T}=2 \mathrm{~K}$ (red), $\Delta \mathrm{T}=3 \mathrm{~K}$ (green) and $\Delta \mathrm{T}=6 \mathrm{~K}$ (blue).

\section{Summary and Conclusions}

Fog is a complex phenomenon that can form in several different ways. Its proper microphysical recovery depends on the knowledge of different atmospheric and cloud properties, such as TWV, fog fraction over a pixel, the existence of thermal inversion and its intensity, fog depth, and fog microphysical structure. In this paper, we showed that some variables can cause significant variations on BT and, consequently, discrepancies in the retrieval of fog microphysical properties.

The sensitivity tests showed that the shorter infrared channels (IR_039 and 
IR_087) were more sensitive to droplet size and longer ones (IR_108 and IR_120) were more sensitive to LWP. A variation in cloud cover had a significant effect on IR_039 and IR_087 BT, but a negligible effect on IR_10 and IR_120. A small displacement of the fog top around the inversion base caused a negligible effect on BT for all channels. However, keeping the same atmospheric profile and placing the fog top higher in the inversion layer caused a notable change on BT, especially for IR_087, IR_108, and IR_120 channels. The effect of water vapor content in the atmosphere was negligible for IR_039. However, a small addition (depletion) of moisture at the low levels $\left(\Delta \mathrm{TWV}= \pm 2.7 \mathrm{~kg} \cdot \mathrm{m}^{-2}\right)$ could rise (drop) the BT up to $0.4 \mathrm{~K}$ for the other channels. All channels suffered considerable changes on BT when the surface temperature was changed, especially for LWP lower than $30 \mathrm{~g} \cdot \mathrm{m}^{-2}$. Variations in thermal inversion intensity had a negligible effect on IR_039. On the other hand, a variation in intensity as high as $3^{\circ} \mathrm{C}$ could cause a variation in BT as high as $0.5^{\circ} \mathrm{C}$ for IR_087, IR_108, and IR_120 channels.

Vertically homogeneous microphysical profile experienced a higher BT than heterogeneous one because homogeneous one had a deeper layer with higher transmissivity at the upper part of the fog so that more radiation was emitted from the fog top towards space. Relative humidity and surface pressure caused no significant change in the BT. A relative humidity variation of $10 \%$ in the fog layer caused a variation in TWV of $0.15 \mathrm{~kg} \cdot \mathrm{m}^{-2}$ and such a small variation wasn't enough to change the BT.

The results revealed that some or all variables combined can significantly change the LUT shape and also cause erroneous retrieval for the fog microphysical properties. LUT convolutions can lead to an inconclusive retrieval of cloud properties for some LUT ranges. [10] found that high cosine of satellite zenith angle can contribute to such a convolution. Based on the sensitivity tests, it seems that the LUT convolution was related to the high fog emissivity and in-fog temperature lapse rate. The process involved in LUT convolution can be divided into two steps. Firstly, BT dropped as a consequence of more and more surface infrared radiation getting trapped in the fog layer, because of fog thickening. BT kept dropping up to a point in which fog started emitting more radiation than the surface towards outer space due to its increasing emissivity. Secondly, as the fog gets optically thicker, a higher in-fog transmissivity gradually shifts upward where the increasing temperature is found due to the inversion layer and, then, the change in BT will be proportional to the in-fog temperature lapse rate.

Precise quantification of the involved errors on the retrieval of the fog microphysical properties may not be possible, because in most of the cases the LUT did not overlap each other.

\section{Acknowledgements}

A special thank to Prof. Andreas Bott, Meteorological Institute, University of Bonn, Germany, for providing the PAFOG model. The author would like to 
thank an anonymous reviewer for improving the manuscript. Partial Financial support was provided by CAPES (Coordination for the Improvement of Higher Education Personnel) and CNPq (National Counsel of Technological and Scientific Development). A.J.P.F was sponsored by CNPQ under grant 302349/2017-6.

\section{Conflicts of Interest}

The authors declare no conflicts of interest regarding the publication of this paper.

\section{References}

[1] WMO, World Meteorological Organization (2008) Guide to Meteorological Instruments and Methods of Observation. Seventh Edition, WMO-No. 8, Geneva.

[2] Unsworth, M.H. and Crossley, A. (1987) Consequences of Cloud Water Deposition on Vegetation at High Elevation. In: Effects of Atmospheric Pollutants on Forests, Wetlands and Agricultural Ecosystems, Springer, Berlin, 171-188.

https://doi.org/10.1007/978-3-642-70874-9 12

[3] Abdel-Aty, M., Ekram, A.-A., Huang, H.L. and Choi, K. (2011) A Study on Crashes Related to Visibility Obstruction Due to Fog and Smoke. Accident Analysis \& Prevention, 43, 1730-1737. https://doi.org/10.1016/j.aap.2011.04.003

[4] Nauss, T. and Kokhanovsky, A.A. (2011) Retrieval of Warm Cloud Optical Properties Using Simple Approximations. Remote Sensing of Environment, 115, 1317 1325. https://doi.org/10.1016/j.rse.2011.01.010

[5] Kokhanovsky, A.A., Rozanov, V.V., Zege, E.P., Bovensmann, H. and Burrows, J.P. (2003) A Semi-Analytical Cloud Retrieval Algorithm Using Backscattered Radiation in 0.4-2.4 $\mu \mathrm{m}$ Spectral Region. Journal of Geophysical Research: Atmospheres, 108, AAC 4-1-AAC 4-19. https://doi.org/10.1029/2001JD001543

[6] Bendix, J. (1995) A Case Study on the Determination of Fog Optical Depth and Liquid Water Path Using AVHRR Data and Relations to Fog Liquid Water Content and Horizontal Visibility. International Journal of Remote Sensing, 16, 515-530. https://doi.org/10.1080/01431169508954416

[7] Kawamoto, K. and Nakajima, T. (2001) A Global Determination of Cloud Microphysics with AVHRR Remote Sensing. Journal of Climate, 14, 2054-2068. https://doi.org/10.1175/1520-0442(2001)014<2054:AGDOCM >2.0.CO;2

[8] Ellrod, G.P. (1995) Advances in the Detection and Analysis of Fog at Night Using GOES Multispectral Infrared Imagery. Weather and Forecast, 10, 606-619. https://doi.org/10.1175/1520-0434(1995)010<0606:AITDAA >2.0.CO;2

[9] Strabala, K.I., Ackerman, S.A. and Menzel, W.P. (1994) Cloud Properties Inferred from 8-12-um Data. Journal of Applied Meteorology, 33, 212-229. https://doi.org/10.1175/1520-0450(1994)033<0212:CPIFD>2.0.CO;2

[10] Merk, C., Cermak, J. and Bendix, J. (2011) Retrieval of Optical and Microphysical Cloud Properties from Meteosat SEVIRI Data at Night-A Feasibility Study Based on Radiative Transfer Calculations. Remote Sensing Letters, 2, 357-366. https://doi.org/10.1080/01431161.2010.523023

[11] Obregon, A., Gehrig-Downie, C., Gradstein, S.R. and Bendix, J. (2014) The Potential Distribution of Tropical Lowland Cloud Forest as Revealed by a Novel MODISBased Fog/Low Stratus Night-Time Detection Scheme. Remote Sensing of Environment, 155, 312-324. https://doi.org/10.1016/j.rse.2014.09.005 
[12] Bugliaro, L., Zinner, T., Keil, C., Mayer, B., Hollmann, R., Reuter, M. and Thomas, W. (2011) Validation of Cloud Property Retrievals with Simulated Satellite Radiances: A Case Study for SEVIRI. Atmospheric Chemistry and Physics, 11, 5603 5624. https://doi.org/10.5194/acp-11-5603-2011

[13] Pérez, J.C., González, A. and Armas-Padilla, M. (2011) Remote Sensing of Water Cloud Properties from MSG/SEVIRI Nighttime Imagery. Remote Sensing of Environment, 115, 738-746. https://doi.org/10.1016/j.rse.2010.10.015

[14] Liu, D.Y., Yang, J., Niu, S.J. and Li, Z.H. (2011) On the Evolution and Structure of a Radiation Fog Event in Nanjing. Advances in Atmospheric Sciences, 28, 223-237. https://doi.org/10.1007/s00376-010-0017-0

[15] Dupont, J.C., Haeffelin, M., Stolaki, S. and Elias, T. (2015) Analysis of Dynamical and Thermal Processes Driving Fog and Quasi-Fog Life Cycles Using the 2010-2013 ParisFog Dataset. Pure and Applied Geophysics, 173, 1337-1358. https://doi.org/10.1007/s00024-015-1159-x

[16] Egli, S., Maier, F., Bendix, J. and Thies, B. (2015) Vertical Distribution of Microphysical Properties in Radiation Fogs: A Case Study. Atmospheric Research, 151, 130-145. https://doi.org/10.1016/j.atmosres.2014.05.027

[17] Mayer, B. and Kylling, A. (2005) Technical Note: The libRadtran Software Package for Radiative Transfer Calculations-Description and Examples of Use. Atmospheric Chemistry and Physics, 5, 1855-1877. https://doi.org/10.5194/acp-5-1855-2005

[18] Stamnes, K., Tsay, S.C. and Laszlo, I. (2000) DISORT, a General-Purpose Fortran Program for Discrete-Ordinate-Method Radiative Transfer in Scattering and Emitting Layered Media: Documentations of Methodology. NASA Technical Report Version 1.1 .

[19] Stamnes, K., Tsay, S.C., Wiscombe, W. and Jayaweera, K. (1988) Numerically Stable Algorithm for Discrete-Ordinate-Method Radiative Transfer in Multiple Scattering and Emitting Layered Media. Applied Optics, 27, 2502-2509. https://doi.org/10.1364/AO.27.002502

[20] Gasteiger, J., Emde, C., Mayer, B., Buras, R., Buehler, S.A. and Lemke, O. (2014) Representative Wavelengths Absorption Parameterization Applied to Satellite Channels and Spectral Bands. Journal of Quantitative Spectroscopy and Radiative Transfer, 148, 99-115. https://doi.org/10.1016/j.jqsrt.2014.06.024

[21] Anderson, G.P., Clough, S.A., Kneizys, F.X., Chetwynd, J.H. and Shettle, E.P. (1986). AFGL Atmospheric Constituent Profiles $(0.120 \mathrm{~km})$. Technical Report. Air Force Geophysics Lab Hanscom AFB MA.

[22] Han, F., Xu, J., He, Y.J., Dang, H.Y., Yang, X.Z. and Meng, F. (2016) Vertical Structure of Foggy Haze over the BeijingeTianjineHebei Area in January 2013. Atmospheric Environment, 139, 192-204. https://doi.org/10.1016/j.atmosenv.2016.05.030

[23] Kong, F.Y. (2002) An Experimental Simulation of a Coastal Fog-Stratus Case Using COAMPS(TM) Model. Atmospheric Research, 64, 205-215.

https://doi.org/10.1016/S0169-8095(02)00092-3

[24] Korolev, A.V., Isaac, G.A., Strapp, J.W., Cober, S.G. and Barker, H.W. (2007) In Situ Measurements of Liquid Water Content Profiles in Mid-Latitude Stratiform Clouds. Quarterly Journal of the Royal Meteorological Society, 133, 1693-1699. https://doi.org/10.1002/qj.147

[25] Bendix, J., Thies, B., Cermak, J. and Naub, T. (2005) Ground Fog Detection from Space Based on MODIS Daytime Data-A Feasibility Study. American Meteorological Society, 20, 989-1005. https://doi.org/10.1175/WAF886.1

[26] Bott, A., Sievers, U. and Zdunkowski, W. (1990) A Radiation Fog Model with a De- 
tailed Treatment of the Interaction between Radiative Transfer and Fog Microphysics. Journal of the Atmospheric Sciences, 47, 2-21.

https://doi.org/10.1175/1520-0469(1990)047<2153:ARFMWA>2.0.CO;2

[27] Zhou, B.B. and Ferrier, B.S. (2008) Asymptotic Analysis of Equilibrium in Radiation Fog. Journal of Applied Meteorology, and Climatology, 47, 1704-1722. https://doi.org/10.1175/2007JAMC1685.1 